\title{
Multifetal Gestation - Maternal and Perinatal Outcome of 112 Pregnancies
}

\author{
Alexander Strauss ${ }^{a}$ Bettina W. Paek ${ }^{c}$ Orsolya Genzel-Boroviczény ${ }^{b}$ \\ Andreas Schulze ${ }^{b}$ Udo J anssen ${ }^{a}$ Hermann Hepp ${ }^{a}$ \\ aDepartment of Obstetrics and Gynecology and 'bepartment of Neonatology, Grosshadern University of Munich, \\ Germany; 'Department of Obstetrics and Gynecology, University of Washington, Seattle, Wash., USA
}

\author{
Key Words \\ Higher order multiple gestation · Triplets · Quadruplets . \\ Quintuplets · Pregnancy outcome · Multifetal pregnancy \\ reduction
}

\begin{abstract}
Purpose: Multifetal pregnancy reduction is a widespread 'therapy' to diminish the risk of prematurity and adverse outcome for the survivors in higher order multiple gestation. The aim of our study was to determine the maternal and neonatal outcome of multifetal pregnancies under a conservative pregnancy management. Study Design: A retrospective review of 112 multifetal pregnancies is presented. All higher order multiple pregnancies delivered after 25 weeks of gestation and managed at a single institution between 1982 and 1999 are included. Results: Triplets, quadruplets and quintuplets were delivered at a mean gestational age of $31+5,29+5$ and $28+4$ weeks, respectively. The perinatal mortality was 14 for triplets and 36 for quadruplets. No quintuplet died in the perinatal period. Respiratory distress syndrome occurred in $23 \%$ of triplets, $65 \%$ of quadruplets and $75 \%$ of quintuplets, intracranial hemorrhage was diagnosed in $14 \%$ of triplets, $15 \%$ of quadruplets and $10 \%$ of quintuplets and retinopathy of prematurity was found in $10 \%$ of triplets, $9 \%$ of quadruplets and $25 \%$ of quintuplets. Discussion: Despite a low neonatal mortality, morbidity of higher
\end{abstract}

order multiple gestations remains significant. Mortality and morbidity are related to preterm delivery but do not exceed the rates of singletons or twins of an identical gestational age. Favorable prognostic landmarks are a gestational age $>30$ weeks and a number of fetuses per pregnancy $\leq 4$. Conclusion: The risks of multifetal pregnancies are significant. Therefore, evidence-based counseling of couples seeking treatment for infertility and prevention of higher order multiple pregnancies through the prudent use of reproductive techniques attains paramount importance.

Copyright @2002 S. Karger AG, Basel

\section{Introduction}

The introduction of modern techniques of reproductive medicine has given rise to a major increase of multifetal pregnancies. The increased incidence of triplet, quadruplet and quintuplet pregnancies poses new and serious medical and ethical problems to parents and obstetricians. The widespread use of multifetal reduction techniques [1-3] stresses the importance of accurate data regarding maternal and fetal outcome of higher order multiple pregnancies. Not only the mere chance of survival, but the chance of intact survival often determines parental choices.

\begin{tabular}{ll}
\hline KARGER & ( ) 2002 S. Karger AG, Basel \\
Fax +4161306 1234 & 1015-3837/02/0174-0209\$18.50/0 \\
$\begin{array}{l}\text { E-Mail karger@karger.ch } \\
\text { www.karger.com }\end{array}$ & $\begin{array}{l}\text { Accessible online at: } \\
\text { www.karger.com/journals/fdt }\end{array}$
\end{tabular}

Alexander Strauss, MD

Department Obstetrics and Gynecology - Grosshadern

Munich University Hospital, Marchioninistrasse 15

D-81377 Munich (Germany), Tel. +49 8970953822

Fax+49897095 3806, E-Mail Alexander.Strauss@helios.med.uni-muenchen.de 
A search of the English literature demonstrates a paucity of data on the mortality and morbidity of multifetal gestations derived from a single institution [4]. To our knowledge, this is the largest series on outcome of multifetal pregnancies at a single tertiary care center. The objective of this study is to determine the fetal and maternal outcome of multifetal pregnancies under a conservative pregnancy management at a single tertiary care referral center.

\section{Methods}

The Department of Obstetrics and Gynecology - Grosshadern, Munich University Hospital, Germany, is a tertiary care perinatal referral center serving metropolitan Munich and southern Bavaria. The study comprised all multifetal pregnancies managed and delivered at our institution between 1982 and 1999.

For the purpose of this study, multifetal gestation was defined as a pregnancy with three or more viable fetuses $>25$ weeks of gestation. Gestational age was calculated by the date of the last known menstruation or the date of conception for patients utilizing assisted reproduction techniques and first trimester ultrasound in all other cases.

Mothers were treated according to a standard protocol. None of the mothers underwent multifetal pregnancy reduction therapy. Bedrest on an in- or outpatient basis was recommended in all cases after reaching viability. Intravenous tocolysis with a $\beta$-sympathomimetic agent (Fenoterol) was initiated for preterm labor or cervical incompetence. A prophylactic tocolytic therapy was not used. Steroid therapy to enhance fetal lung maturity was given repetitively every 10 days starting at $24+5$ weeks (since 1984). This has recently (since 1999) been limited to three doses due to concerns over steroid effects on the developing fetus pending further investigations [5]. Antibiotics (firstline antibiotics: penicillin, cephalosporin, clarithromycin; secondline: imipenem, erythromycin) were prophylactically administrated before 30 weeks. In case of intrauterine infection after 30 weeks, treatment was continued until clinical and/or biochemical infection parameters disappeared. All pregnancies were followed with serial fetal ultrasonographic examinations every 4 weeks until viability. After 25 weeks, time intervals of routine sonography were cut to 14 days. Discordant fetal growth was monitored with Doppler studies to evaluate placental perfusion (since 1988) and repeated scans to determine interval growth at 10-14 days. Nonstress tests were initiated at viability at weekly intervals for outpatients and daily for inpatients.

All neonates were resuscitated by two neonatologists. Surfactant therapy has been available since 1991 and was administered at the discretion of the neonatology staff depending on oxygen requirement, oxygen saturation and ventilation pressure.

The diagnosis of respiratory distress syndrome (RDS) was based on dyspnea, $\mathrm{PaO}_{2}<50 \mathrm{~mm} \mathrm{Hg}$ in the absence of oxygen supplementation and typical chest radiograph findings. Bronchopulmonary dysplasia (BPD) was defined as the need of oxygen supplementation after 28 days of life. The diagnosis chronic lung disease (CLD) was made when oxygen supplementation was required at the calculated time of 36 weeks of gestation. Retinopathy of prematurity (ROP) was graded according to its international classification [6]. The diagnosis of necrotizing enterocolitis (NEC) was based on typical clinical and radiographic findings [7]. All infants underwent ultrasonographic examination of the head to detect intracranial hemorrhage (ICH).

Early neonatal mortality was defined as number of deaths of liveborn infants weighing $\geq 500 \mathrm{~g}$ in the first 7 days of life per 1,000 liveborn infants. Late neonatal mortality was defined as the number of deaths of liveborn infants after 7 days, but before 28 days of life per 1,000 liveborn infants. Perinatal mortality was defined as the sum of fetal deaths $>24$ weeks in addition to the early neonatal deaths. Postneonatal deaths were defined as the number of deaths after 28 days, but before 1 year of age per 1,000 livebirths.

Fetal mortality and morbidity were compared to historic series of higher order multiple pregnancies and, on the other hand, to a current control group of all singleton and twin pregnancies delivered at a corresponding gestational age between 1988 and 1994 at our department. Therefore, the study and control newborns were matched for prematurity as the primary factor for perinatal morbidity and mortality. The study period, comparable in higher order multiples and controls, was chosen to represent equally both the era before and after the availability of surfactant in neonatal intensive care (1991).

Medical charts of mother and infants were reviewed covering the period until final discharge from hospital. For all quadruplet and quintuplets, follow-up included neurological and developmental assessment by a child development specialist at a corrected age of 3-5 months and subsequently after 1, 2 and 4 years. All children younger than 24 months were subjected to the Griffith test to assess motor and mental development. One set of quintuplets born in 1998 and one set of quadruplets born in 1999 have not completed all follow-up examinations due to their age (but as far as analyzed, develop normal).

Statistical analysis was performed using the $\bar{\chi}$ test and Student's $\mathrm{t}$ test when appropriate. A $\mathrm{p}$ value $\leq 0.05$ was considered significant.

\section{Results}

Among 26,693 deliveries between 1982 and 1999, 112 multifetal pregnancies occurred at the Department of Obstetrics and Gynecology - Grosshadern, Munich University Hospital. These consisted of 94 sets of triplets, 14 sets of quadruplets and 4 sets of quintuplets. The incidence of multifetal pregnancies was thus 1:284 for triplets, 1:1,907 for quadruplets and 1:6,673 for quintuplets.

\section{Prenatal Management}

Of the 112 women, 16 patients conceived spontaneously (14.4\%), 63 patients (56\%) after in vitro fertilization, gamete intrafallopian transfer or intracytoplasmatic sperm injection, $21(18.8 \%)$ after induction of ovulation, $6(5.3 \%)$ following insemination and $5(4.4 \%)$ conceived with the aid of a combination of ovulation induction and insemination.

Admission to the hospital for patients with triplet, quadruplet and quintuplet pregnancies occurred at a mean 
Table 1. Maternal complications in multifetal gestation

\begin{tabular}{lllll}
\hline & $\begin{array}{l}\text { Triplet } \\
\text { pregnancies } \\
(\mathrm{n}=94)\end{array}$ & $\begin{array}{l}\text { Quadruplet } \\
\text { pregnancies } \\
(\mathrm{n}=14)\end{array}$ & $\begin{array}{l}\text { Quintuplet } \\
\text { pregnancies } \\
(\mathrm{n}=4)\end{array}$ & Total \\
$(\mathrm{n}=112)$
\end{tabular}

gestational age of $27+3,25+0$ and $24+4$ weeks respectively. The pregnancy prolongation achieved after hospitalization was 30 days for triplets, 38 days for quadruplets and 24 days for quintuplets.

Twenty-five women underwent a prophylactic cerclage between 12 and 21 weeks. Both Shirodkar's and McDonald's technique were performed. Sixteen carried triplets (17\% of all triplet pregnancies, 16/94), 6 quadruplets (43\% of all quadruplet pregnancies, 6/14) and 3 quintuplets ( $75 \%$ of all quintuplet pregnancies, $3 / 4$ ).

Premature labor or cervical incompetence occurred in 60/94 triplets (64\%), 12/14 quadruplets (86\%) and all quintuplet pregnancies. Intravenous fenoterol was administrated in triplet pregnancies for a mean of $14.1(0-51)$ days, in quadruplet pregnancies for $27.6(0-51)$ days and quintuplet pregnancies for 5 (2-13) days. Preterm premature rupture of membranes (P-PROM) occurred in 26 of 112 pregnancies $(23 \%)$, chorioamnionitis (uterine tenderness, serologic signs of infection, persistent labor despite tocolysis, putrid vaginal discharge, maternal fever) in 5 $(5 \%)$ and preeclampsia, defined according to the classification of the International Society for the Study of Hypertension in Pregnancy (ISSHP, 1986), in 6 of the 112 pregnancies (5\%). Compared to other studies [8]-17-44\% for triplet mothers and $32-67 \%$ for quadruplets mothers the low incidence of preeclampsia in our data could be related to earlier delivery (see table 6). Maternal complications are detailed in table 1.

\section{Multifetal Growth}

Compared to singleton and twin newborns, higher order multiples tend to weigh less at birth. The percentage of growth retardation, defined as birth weight $\leq 10$ th per- centile of singleton nomograms published by Hadlock et al. [9], was 46\% (129/281) for triplets, 50\% (27/54) for quadruplets and $55 \%(11 / 20)$ for quintuplets. Fetal sex did not influence the birth weight significantly. Standard biometry in triplets (biparietal diameter, abdominal circumference and femur length) proved to have a characteristic growth pattern. Until 27 weeks, the 50th percentile of triplets was higher (mean $2.2-10.4 \mathrm{~mm}$ ) than in singletons. Multifetal growth flattened compared to singletons between 27 and 31 weeks. It finally crossed and fell short of the 50th percentile for singletons during the 31st week. Fetuses from quadruplet and quintuplet pregnancies paralleled the course of triplets.

\section{Labor and Delivery}

All deliveries were by cesarean section except for one triplet pregnancy that was delivered precipitously at 26 weeks immediately after arrival in the Labor and Delivery Suite. Regarding the indication for delivery, a distinction was made between maternal and fetal indications if possible. Maternal indications included cardiac, pulmonary, gastrointestinal or general physical or psychological decompensation and preeclampsia (44\%, 41/94 for triplets, $43 \%, 6 / 14$ for quadruplets, and $25 \%, 1 / 4$ for quintuplets), preterm labor $(38 \%, 36 / 94$ for triplets, $50 \%, 7 / 14$ for quadruplets, and $75 \%, 3 / 4$ for quintuplets) as well as PPROM (19\%, 18/94 for triplets, 43\%, 6/14 for quadruplets, and $50 \%, 2 / 4$ for quintuplets) and cervical incompetence $(11 \%, 10 / 94$ for triplets, $21 \%, 3 / 14$ for quadruplets, and $50 \%, 2 / 4$ for quintuplets).

Fetal indications were defined as growth retardation of one or several fetuses $(25 \%, 23 / 94$ for triplets, $21 \%, 3 / 14$ for quadruplets and $25 \%, 1 / 4$ for quintuplets), fetal dis- 
Table 2. Survival and mortality of children from multifetal pregnancies

\begin{tabular}{|c|c|c|c|c|}
\hline & $\begin{array}{l}\text { Triplets } \\
(\mathrm{n}=282)\end{array}$ & $\begin{array}{l}\text { Quadruplets } \\
(\mathrm{n}=55)\end{array}$ & $\begin{array}{l}\text { Quintuplets } \\
(\mathrm{n}=20)\end{array}$ & $\begin{array}{l}\text { Total } \\
(\mathrm{n}=357)\end{array}$ \\
\hline Stillbirths $>25+0$ SSW & $1(3.5 \%)$ & $1(18.2 \%)$ & & $2(5.6 \%)$ \\
\hline Early neonatal mortality ${ }^{1}$ & $3(10.6 \%)$ & $1(18.2 \%)$ & & $4(11.2 \%)$ \\
\hline Late neonatal mortality ${ }^{2}$ & $4(14.1 \% 0)$ & & $1(50 \% 0)$ & $5(14.0 \%)$ \\
\hline Perinatal mortality ${ }^{3}$ & $4(14.1 \% 0)$ & $2(36.4 \%)$ & & $6(16.8 \%)$ \\
\hline Post neonatal mortality 4 & $1(3.5 \%)$ & $1(18.2 \%)$ & $2(100 \%)$ & $4(11.2 \%)$ \\
\hline Survival to discharge from hospital & $273 / 282(968 \%)$ & $52 / 55(945 \%)$ & $17 / 20(850 \%)$ & $342 / 357(958 \%)$ \\
\hline \multicolumn{5}{|c|}{1 Early neonatal mortality: 0-7 days postnatal per 1,000 livebirths. } \\
\hline \multicolumn{5}{|c|}{ Late neonatal mortality: $8-28$ days postnatal per 1,000 livebirths. } \\
\hline \multicolumn{5}{|c|}{ Perinatal mortality: stillbirths and early neonatal deaths per 1,000 livebirths. } \\
\hline \multicolumn{5}{|c|}{ Postneonatal (infant) mortality: 28 days- 1 year per 1,000 livebirths. } \\
\hline
\end{tabular}

tress $(17 \%, 16 / 94$ for triplets, $29 \%, 4 / 14$ for quadruplets and $0 / 4$ for quintuplets), and chorioamnionitis (3\%,3/94 for triplets, $0 / 14$ for quadruplets and $25 \%, 1 / 4$ for quintuplets).

\section{Neonatal Outcome}

The 112 multifetal pregnancies resulted in 355 livebirths. For the higher order multiples studied, mean gestational age at birth for triplets was $31+5$ weeks $(25+0$ to $36+3)$, for quadruplets $29+5$ weeks $(25+3$ to $32+3)$, and for the quintuplets $28+4$ weeks $(27+3$ to $30+6)$. The mean birth weight for triplets was $1,437 \mathrm{~g}(550$ $2,420)$, for quadruplets $1,128 \mathrm{~g}(490-2,000)$ and for quintuplets $1,030 \mathrm{~g}(670-1,870)$. The mean placental weight of triplet, quadruplet and quintuplet pregnancies was 1,048 , 1,174 and $1,260 \mathrm{~g}$, respectively. This corresponded to 19 , 21 and $20 \%$ of the mean total weight (fetal weights plus placenta). There was no significant difference in gestational age at birth between patients that had received a cerclage and those that did not, or between different modes of conception. Of all newborns, 10\% (32/355) had an Apgar score after $5 \mathrm{~min}$ of live $<7$, and $14 \%$ were (pre)acidemic (51/355) defined as an arterial $\mathrm{pH}<7.25$.

\section{Mortality}

Of the 355 liveborn infants, 12 died (3.38\%) before being discharged from hospital. $97.2 \%(273 / 282)$ of triplets, $94.5 \%(52 / 55)$ of quadruplets and $85 \%(17 / 20)$ of quintuplets survived (table 2). No children with lethal anomalies were among the studied higher order multiples. Only 2 infants had congenital anomalies; 1 Cornelia de Lange syndrome and $1 \mathrm{a}$ complex heart defect (double outlet right ventricle combined with ventricular septal defect). Both fetuses had been growth retarded but neither the heart defect nor the syndrome had been diagnosed prenatally. There were 2 fetal deaths $>25$ weeks, 1 in a triplet pregnancy and 1 in a quadruplet pregnancy. The early neonatal mortality rate for triplets, quadruplets and quintuplets was $10.6,18.2$ and 0 respectively. Thus, the perinatal mortality was $14.1,36.4$ and 0 . The late neonatal mortality rate for triplets and quintuplets was 14.1 and 50. Cause for the losses was RDS $(n=3)$, lung hypoplasia $(\mathrm{n}=2), \mathrm{ICH}(\mathrm{n}=2)$, sepsis $(\mathrm{n}=2)$, and acute heart failure, shock and polyuric kidney failure $(\mathrm{n}=1$ each). There were 4 postneonatal deaths: 1 each amongst the triplets and quadruplets, and 2 amongst the quintuplets. Causes for postneonatal death were polyuric renal failure, sepsis, respiratory failure and protracted shock.

The mortality rate for singleton and twin infants at our institution for a comparable period of time (1988-1994) was $39.1(68 / 1,739)$. Even when adjusted for gestational age at birth, there was no significant difference in mortality of infants from triplet and quadruplet pregnancies compared to singleton/twin pregnancies from 26 weeks on. Only very low gestational age ( $<27$ weeks) or a high number of fetuses per pregnancy $(>4)$ increases the mortality risk compared to controls (table 3 ).

After 30 weeks, there were no neonatal and fetal losses while at lower gestational age ( $<30$ weeks) $10 \%(9 / 92)$ of triplets, $11 \%(3 / 27)$ of quadruplets and $20 \%(3 / 15)$ of quintuplets died. Due to the limited number of pregnancies with more than 3 fetuses, statistical significance is only reached in triplets $(p<0.01)$. The predictive value of gestational age in terms of fetal and neonatal losses is also present in the control pregnancies: mortality in singleton and twin pregnancies delivered before 30 weeks was $8 \%$, 
Table 3. Mortality of children from higher order multiple pregnancies ( $>25$ weeks) according to gestational age, compared to controls (singletons/twins, 1988-1994)

\begin{tabular}{|c|c|c|c|c|c|c|c|}
\hline Weeks & Triplets & & Quadruplets & & Quintuplets & & Singletons/twins \\
\hline 26 & $4 / 9(44 \%)$ & $\mathrm{p}=0.05^{*}$ & $2 / 3(66 \%)$ & $\mathrm{p}=0.03^{*}$ & & & $12 / 71(17 \%)$ \\
\hline 27 & $3 / 15(20 \%)$ & & & & $2 / 5(40 \%)$ & $\mathrm{p}=0.08$ & \\
\hline 28 & $0 / 24(0 \%)$ & $\mathrm{p}=0.8$ & $1 / 4(25 \%)$ & $\mathrm{p}=0.1$ & $1 / 10(10 \%)$ & $\mathrm{p}=0.08$ & $10 / 142(/ \%)$ \\
\hline 29 & $1 / 12(8 \%)$ & & $0 / 8(0 \%)$ & & & & \\
\hline 30 & $1 / 32(3 \%)$ & $\mathrm{p}=0.13$ & $0 / 12(0 \%)$ & $\mathrm{p}=0.14$ & & $\mathrm{p}=0.56$ & $20 / 315(6 \%)$ \\
\hline 31 & $0 / 45(0 \%)$ & & $0 / 12(0 \%)$ & & $0 / 5(0 \%)$ & & \\
\hline 32 & $0 / 45(0 \%)$ & $p=0.08$ & $0 / 12(0 \%)$ & $p=0.55$ & & & $26 / 1.211(2 \%)$ \\
\hline$>32$ & $0 / 99(0 \%)$ & $p=0.08$ & $0 / 4(0 \%)$ & $p=0.53$ & & & $20 / 1,211(2 \%)$ \\
\hline Total & $9 / 281(3.20 \%)$ & $\mathrm{p}=0.57$ & $3 / 55(5.45 \%)$ & $\mathrm{p}=0.56$ & $3 / 20(15 \%)$ & $\mathrm{p}=0.01^{*}$ & $68 / 1,739(3.91 \%)$ \\
\hline
\end{tabular}

* Significant difference.

Table 4. Neonatal complications in multifetal gestation

\begin{tabular}{|c|c|c|c|c|}
\hline & $\begin{array}{l}\text { Triplets } \\
(\mathrm{n}=281)\end{array}$ & $\begin{array}{l}\text { Quadruplets } \\
(\mathrm{n}=54)\end{array}$ & $\begin{array}{l}\text { Quintuplets } \\
(\mathrm{n}=20)\end{array}$ & $\begin{array}{l}\text { Total } \\
(\mathrm{n}=355)\end{array}$ \\
\hline Respiratory distress syndrome & $63(23 \%)$ & $35(65 \%)$ & $15(75 \%)$ & $115(32 \%)$ \\
\hline Bronchopulmonary dysplasia & $2(1 \%)$ & $11(20 \%)$ & $3(15 \%)$ & $16(5 \%)$ \\
\hline Chronic lung disease & $1(0.4 \%)$ & $2(4 \%)$ & $1(5 \%)$ & $4(1 \%)$ \\
\hline Intracranial hemorrhage $\mathrm{I}^{\circ}-\mathrm{II}^{\circ}$ & $25(9 \%)$ & & $1(5 \%)$ & $26(7 \%)$ \\
\hline Intracranial hemorrhage $\mathrm{III}^{\circ}-\mathrm{IV}^{\circ}$ & $13(5 \%)$ & $8(15 \%)$ & $1(5 \%)$ & $22(6 \%)$ \\
\hline Retinopathy of prematurity $\mathrm{I}^{\circ}-\mathrm{II}^{\circ}$ & $23(8 \%)$ & & $1(5 \%)$ & $24(7 \%)$ \\
\hline Retinopathy of prematurity $\mathrm{III}^{\circ}-\mathrm{IV}^{\circ}$ & $5(2 \%)$ & $5(9 \%)$ & $4(20 \%)$ & $14(4 \%)$ \\
\hline Pneumothorax & $8(3 \%)$ & $2(4 \%)$ & $3(15 \%)$ & $13(4 \%)$ \\
\hline Patent ductus arteriosus & $15(5 \%)$ & $3(6 \%)$ & $2(10 \%)$ & $20(6 \%)$ \\
\hline Necrotizing enterocolitis & $7(2 \%)$ & & $2(10 \%)$ & $9(3 \%)$ \\
\hline Hydrocephalus & $4(1 \%)$ & $2(4 \%)$ & $1(5 \%)$ & $7(2 \%)$ \\
\hline
\end{tabular}

$42 / 528$ versus $2.2 \%, 26 / 1,211$ in mothers delivering after 30 weeks $(\mathrm{p}<0.01)$.

\section{Neonatal Complications}

The mean duration of hospitalization amongst the triplets was 30 days, 38 days for quadruplets and 24 days for quintuplets. The incidence of neonatal complications (RDS, ICH, ROP, NEC, pneumothorax, hydrocephalus) is listed in table 4. Neonatal health impairment correlated with low gestational age at birth and a high number of fetuses per pregnancy (table 5). Before 30 weeks, $41 \%$ (34/ $84)$ of triplets, $54 \%(13 / 24)$ of quadruplets and $75 \%(9 / 12)$ of quintuplets showed some degree of health impairment. After 30 weeks, only 25\% (48/189) of triplets, 14\% (4/28) of quadruplets and none of the 5 quintuplets showed signs of health impairment. These data define a statistical significant difference for each category of multiples (triplets $p=0.01$, quadruplets $p=0.02$ and quintuplets $p=0.05$ ) Health impairment in singleton and twin controls (before 30 weeks: $58 \%, 281 / 486$ versus after 30 weeks: $8 \%, 89 /$ $1,185)$ is reduced by growing gestational age in the same way $(\mathrm{p}<0.01)$.

All quadruplets and quintuplets underwent developmental assessment at defined intervals. Of these 69 children, $53(77 \%)$ are considered normal on developmental assessment and do not have a neurological deficit. Four children $(6 \%)$ were diagnosed with a mild neurological deficit (1 with muscular hypotonia, 1 (2\%) with muscular hypertonia, and $2(3 \%)$ with hyperexcitability). Four children $(6 \%)$ were assessed with delayed mental and motor 
Table 5. Health impairment in surviving children from higher order multiple pregnancies ( $>25$ weeks) according to gestational age, compared to controls (singletons/twins, 1988-1994).

\begin{tabular}{|c|c|c|c|c|c|c|c|}
\hline Weeks & Triplets & & Quadruplets & & Quintuplets & & Singletons/twins \\
\hline 26 & $3 / 5(60 \%)$ & $\mathrm{p}=0.31$ & $1 / 1(100 \%)$ & \multirow{3}{*}{$\begin{array}{l}\mathrm{p}=0.61 \\
\mathrm{p}=0.74\end{array}$} & & \multirow{3}{*}{$\mathrm{p}=1.00$} & $47 / 59(80 \%)$ \\
\hline 27 & $5 / 12(42 \%)$ & \multirow[t]{2}{*}{$\mathrm{p}=0.00^{*}$} & & & $3 / 3(100 \%)$ & & \multirow{2}{*}{$99 / 132(75 \%)$} \\
\hline 28 & $8 / 24(33 \%)$ & & $2 / 3(66 \%)$ & & $6 / 9(67 \%)$ & & \\
\hline 29 & $3 / 11(27 \%)$ & \multirow{3}{*}{$p=0.36$} & $7 / 8(88 \%)$ & \multirow{3}{*}{$\mathrm{p}=0.37$} & & \multirow{3}{*}{$\mathrm{p}=0.04^{*}$} & \multirow{3}{*}{$135 / 295(46 \%)$} \\
\hline 30 & $15 / 31(48 \%)$ & & $3 / 12(25 \%)$ & & & & \\
\hline 31 & $17 / 45(38 \%)$ & & $2 / 12(17 \%)$ & & $0 / 5(0 \%)$ & & \\
\hline 32 & $17 / 45(38 \%)$ & \multirow{2}{*}{$\mathrm{p}=0.00^{*}$} & $2 / 12(17 \%)$ & & $\mathrm{p}=0.45$ & & \multirow{2}{*}{$89 / 1,185(8 \%)$} \\
\hline$>32$ & $14 / 99(14 \%)$ & & $0 / 4(0 \%)$ & & & & \\
\hline Total & $82 / 272(30 \%)$ & $\mathrm{p}=0.00^{*}$ & $17 / 52(33 \%)$ & $\mathrm{p}=0.07$ & $9 / 17(53 \%)$ & $\mathrm{p}<0.01^{*}$ & $370 / 1,671(22 \%)$ \\
\hline
\end{tabular}

* Significant difference.

development without specific neurological deficit, and 5 children $(7 \%)$ were diagnosed with cerebral palsy $(\mathrm{CP}$, defined as athetoid impairment of movements as a result of perinatal cerebral hypoxia). Three children (4\%) showed an isolated motor development deficiency; in 2 of these a concurrent BPD was assumed to be the underlying cause [28].

Overall, 70\% (190/272) of the surviving triplets, $67 \%$ $(35 / 52)$ of quadruplets and $47 \%(8 / 17)$ of quintuplets were discharged from hospital without handicap after 44 (12129), 84 (45-158) and 80 (43-198) days respectively.

\section{Distribution of Mortality and Morbidity amongst \\ Families}

Of all 94 families with triplets, $41(44 \%)$ had at least 1 impaired child, and 7 (7\%) had suffered a neonatal loss (intrauterine fetal demise included). Amongst 14 parents of quadruplets, $9(64 \%)$ had an impaired child and 2 $(14 \%)$ had suffered a neonatal loss. Two of the four families $(50 \%)$ with quintuplets had at least 1 impaired child, and the same two families (50\%) had suffered a neonatal loss.

\section{Discussion}

More than 2 fetuses at a time multiply the probability for an unfavorable pregnancy outcome. Different strategies, multifetal pregnancy reduction techniques (fetocide) versus conservative prenatal management, are used to optimize the fetal and maternal outcome. The perinatal mortality of multifetal gestation has decreased signifi- cantly over the past decades (table 6). Both the number of stillbirths and postnatal deaths contributed to the decline, attesting to improved perinatal and neonatal care (table 2).

\section{Prenatal Management}

Different management schemes to prolong the pregnancy such as prophylactic admission to the hospital for bedrest, oral tocolysis, intravenous tocolytics or cervical cerclage differ in their effectiveness [10].

Preterm labor is the most frequent complication in multifetal pregnancies. A positive effect in the management of premature labor and/or cervical incompetence has been experienced with bedrest and intravenous tocolytics. A hospital setting allows thorough fetal and maternal monitoring, but due to the lack of a control group its effect on a prolongation of pregnancy after the onset of preterm labor, cervical incompetence or P-PROM cannot be evaluated. In twins, an increase of placental perfusion through bedrest has been shown to reduce the number of fetuses with intrauterine growth retardation after 30 weeks [11] and preterm delivery [12]. Nevertheless, remarkable costs and physical as well as psychological maternal stress are to be considered [13]. Clinical observation suggests a prolongation of gestation by individually adapted bedrest and intravenous tocolysis. In combination with betamethasone, adequate surveillance is needed because of the increased risk of maternal pulmonary edema. However, the prophylactic administration of tocolytics still lacks objective data [14-16].

The use of a prophylactic cerclage in multifetal pregnancy is still controversial [17]. A comparison of the mul- 
Table 6. Reports on perinatal outcome in triplet pregnancies [modified from 10])

\begin{tabular}{llclc}
\hline Authors & $\begin{array}{l}\text { Study } \\
\text { period }\end{array}$ & Pregnancies & $\begin{array}{l}\text { Gestational } \\
\text { age, weeks }\end{array}$ & $\begin{array}{l}\text { Perinatal } \\
\text { mortality }, \% 0\end{array}$ \\
\hline Kurtz & $1931-1956$ & 21 & & 333 \\
Itzkowic & $1946-1976$ & 59 & $33+4$ & 232 \\
Deale & $1967-1976$ & $367^{\mathrm{b}}$ & & 182 \\
Daw & $1958-1977$ & 14 & $34+5$ & 310 \\
Holcberg & $1960-1979$ & 31 & $31+6$ & 312 \\
Loucopoulos & $1965-1981$ & 27 & $35+6$ & $83^{\mathrm{c}}$ \\
Berg & $1973-1981$ & 8 & & 40 \\
Syrop & $1946-1983$ & 20 & $33+3$ & 216 \\
Weissman & $1978-1987$ & 29 & $33+3$ & 138 \\
Lipitz & $1975-1988$ & 78 & $33+1$ & 93 \\
Arlettaz & $1985-1988$ & $77^{\mathrm{d}}$ & $33+0$ & 89 \\
Newman & $1985-1988$ & $198^{\mathrm{e}}$ & $33+1$ & 66 \\
Levene & 1989 & $143^{\mathrm{f}}$ & 33 & 77 \\
Seoud & $1982-1990$ & 15 & $31+6$ & 0 \\
Boulot & $1985-1990$ & 33 & $34+1$ & $42^{\mathrm{g}}$ \\
Peaceman & $1988-1991$ & 15 & $34+5$ & 0 \\
Albrecht & $1989-1994$ & 57 & $33+0$ & 41 \\
Skrablin & $1986-1997$ & 52 & $32+6$ & $167^{\mathrm{h}}$ \\
Strauss & $1983-1999$ & 94 & $31+5$ & $14^{\mathrm{i}}$ \\
\hline
\end{tabular}

a Intrauterine and neonatal mortality $\geq 20$ weeks.

b Pooled data from 150 hospitals.

Intrauterine and neonatal mortality $\geq 28$ weeks.

Review of data from entire Switzerland.

Pooled data from 24 centers.

Review of data from England and Wales.

Exclusion from 3 children died in the 21 st week.

Perinatal mortality $\geq 24$ weeks.

Perinatal mortality $>25$ weeks. tifetal pregnancies studied shows no positive effect on the length of gestation, birth weight or facilitation of pregnancy management (bedrest, gestational age at hospitalization, need for tocolysis) and hence we do not advocate its use [18].

\section{Gestational Age and Birth Weight}

Premature birth becomes more likely with an increasing number of fetuses, whereas birth weight of the newborns decreases. These rather intuitive findings support the theory of a limited uterine capacity $[19,20]$. However, the mean total weight (fetuses and placenta) for triplet, quadruplet and quintuplet pregnancies differed between 5,317 and $6,720 \mathrm{~g}$, with quintuplet pregnancies reaching the highest intrauterine weight. Thus, the same degree of 'intrauterine crowding' and therefore mechanical strain is not regularly reached in pregnancies with 3 or 4 fetuses and does not seem to be the limiting factor in every case.

\section{Growth Curve}

The growth curve of higher order gestation fetuses parallels the 25th percentile of singleton growth curves until 27 weeks [21]. Collins and Bleyl [22] have described that beyond the 32nd week, multifetal growth slows down. Our data confirmed and specified this growth pattern. The use of growth nomograms from singleton pregnancies overestimates intrauterine growth retardation in higher order multiple gestation beginning from 27 weeks. As a consequence, individual decisions on delivery due to placental insufficiency of 1 or more fetuses are at risk of being made on the basis of maladapted growth curves.

Furthermore, discordant growth leads to difficult obstetric compromises (intrauterine monitoring, timing of intervention), saving 1 fetus from intrauterine fetal damage and exposing its sibling to prematurity. Two of our triplet pregnancies were delivered at 29 weeks because of a severe growth retardation of 1 fetus. One infant was found to have Cornelia de Lange syndrome and another in an other triplet pregnancy a severe cardiac anomaly. Both infants did not survive secondary to their anomaly and did not profit from early delivery. Their siblings were thus exposed to 'unnecessary' prematurity. Prolongation of pregnancy and hence decreased risk of prematurity need to be carefully weighed against the risk of intrauterine placental insufficiency to one or more fetuses.

\section{Mode of Delivery}

From our point of view, an elective cesarean section is the preferred mode of delivery for multifetal pregnancies, as these are most likely premature. Not only does a cesarean section avoid the risks associated especially with vaginal operative deliveries, but ensures optimal logistic conditions (e.g. two experienced neonatologists per child) to give these infants the best possible start in life.

\section{Neonatal Outcome}

In our study, we were not able to demonstrate an increased risk for triplets and quadruplets compared to singleton or twin gestation. The perinatal mortality is comparable to the figures from preterm singleton and twin infants at the same gestational age except for very immature triplets and quadruplets (26 weeks) and excessive intrauterine crowding ( $>4$ fetuses) (table 3 ).

Mean gestational age for triplet pregnancies in prior series is slightly higher (1 week) compared to our study. Perinatal mortality in comparison dropped to a minimum 
of 14 (table 6). As suggested by Holcberg et al. [23], this may be attributable to early diagnosis of a multifetal pregnancy. $85 \%$ of pregnancies studied resulted from sterility treatment. Careful prenatal surveillance (ultrasound, Doppler, cardiotocography, hospitalization) and intrauterine risks, which are more common in multifetal gestation, led to earlier delivery. Fetal distress and fetal deaths have been reduced. Furthermore, advances in neonatology (early surfactant administration) and care in a highly skilled intensive care nursery (high-frequency ventilation) may have contributed to the low neonatal mortality.

One could speculate that this reduction in mortality (compared to table 6), especially of intrauterine fetal demise after fetuses reached viability ( $>25$ weeks), is accompanied by a concomitant increase in neonatal morbidity. Regarding the parameters for early neonatal morbidity ( $\mathrm{pH}$, Apgar score), no augmented risk relative to controls of similar gestational ages could be found. However, the rate of RDS and PDA in our study is identical or even lower than previously reported, whereas the incidence of severe $\mathrm{ICH}\left(\mathrm{III}^{\circ}-\mathrm{IV}^{\circ}\right)$ in our series is slightly higher [10, 24]. At our center, all premature infants, not only those considered at risk for $\mathrm{ICH}$, received a cranial sonography. Thus, even asymptomatic children with mild ICH were diagnosed. As an isolated finding, the incidence of ROP $\mathrm{III}^{\circ}-\mathrm{IV}^{\circ}$ (triplets $2 \%$, quadruplets $9 \%$, quintuplets $20 \%$ ) and as a sequel severe hyperopia ( $>+4$ dioptry), myopia $(<-4$ dioptry) or blindness was increased over singleton gestation. This phenomenon has been observed in twin gestations $[22,25]$ and has not yet been explained. Our data confirm the results of the Cooperative Study of Retrolental Fibroplasia [26] that a multiple pregnancy defines an isolated risk for visual impairment.

Compared to other investigations $[8,27]$ in singletons $(1 \%)$ and multiples $(1.3 \%)$ the rate of major congenital anomalies in our study was low $(0.6 \%)$. Despite the rather large series of newborns analyzed, we interpret this discrepancy to be derived from the limits in study size.

Our results show that accurate prenatal monitoring, the use of adapted growth percentiles and advancing neonatal expertise have allowed a dramatic reduction of intrauterine and postnatal mortality compared to former series. Also, although the trend has moved towards delivery at earlier gestational age, this has not led to a rise in morbidity. Thus, advances in perinatal medicine have allowed us to achieve a decrease in mortality without the cost of increased morbidity.

Children of multifetal pregnancies are challenged by long-term physical health impairment. In twins, the risk of $\mathrm{CP}$ is described to be $6.6-7.4 \%$ and therefore 4 -fold higher than in singletons $(1.6-2.4 \% 0) .15-32 \% 0$ of triplets develop CP, this means a 3- to 5-fold increase compared to twins. Quadruplets and quintuplets face a $\mathrm{CP}$ rate of 77-85\%0 (3- to 5-fold of triplets). Before 32 weeks, CP occurs in singletons, twins and quadruplet/quintuplets in 9,12 and $8.5 \%$ respectively [28, 29]. Developmental assessment of all analyzed quadruplets and quintuplets in our series (CP 73\% ) confirmed the data from the literature.

As expected, quintuplets had the least favorable prognosis regarding morbidity and mortality. Only 8 of 17 quintuplet neonates (47\%) survived without even a mild handicap, whereas quadruplets -35 out of $52(67 \%)$ - and triplets -190 out of $272(70 \%)$ - survived without health impairment. Table 5 details the chances of intact survival in relation to gestational age. Gestational age shows a close correlation to morbidity and mortality. Triplets born before 30 weeks had a 1.85 times relative risk for morbidity and mortality compared to those born after 30 weeks. Among quadruplets born after 30 weeks, the factor of risk reduction is 4.15 . All impaired quintuplets were born before 29 weeks. However, the incidence of a deceased or impaired child relative to families shows that only $50 \%(47 / 94)$ of couples with triplets and $36 \%(5 / 14)$ with quadruplet and $25 \%(1 / 4)$ quintuplet pregnancies respectively were unaffected.

In conclusion, the risk of multifetal pregnancies remains significant. Maternal morbidity is chiefly related to preterm labor. Fetal morbidity and mortality is mainly related to prematurity but is not significantly increased in singletons and twins of similar gestational age after 26 weeks. Intensive prenatal monitoring may detect early signs of fetal compromise. Timely delivery and excellent neonatal care may significantly lower perinatal mortality. In terms of risk assessment, gestational age over 30 weeks and a maximum of 4 fetuses per pregnancy define prognostic landmarks. However, even optimal use of resources leaves more than every second family to cope with a dead or impaired child.

Multifetal pregnancy reduction (feticide) is ethically problematic and difficult to accept for some patients and therefore should not be part of routine (infertility) treatment planning. The presented data establish the basis for a counterbalance in counseling couples seeking treatment for infertility and advocate the prudent use of modern reproductive techniques to prevent multifetal pregnancies. 


\section{References}

1 Evans MI, Dommergues M, Wapner RJ, Goldberg JD, Lynch L, Zador IE, Carpenter RJ Jr, Timor-Tritsch I, Brambati B, Nicolaides KH Dumez Y, Monteagudo A, Johnson MP, Golbus MS, Tului L, Polak SM, Berkowitz RL: International collaborative on multifetal pregnancy reduction (MFPR): Dramatically improved outcomes with increased experience. Am J Obstet Gynecol 1999; 180:28.

2 Von Dadelszen P, Johnson JA, Farquharson DF, Wilson RD, Seaward PG: Multifetal pregnancy reduction and selective termination: The Canadian experience. Fetal Diagn Ther 1999; 14:360-364.

3 Britt DW, Mans M, Risinger ST, Evans MI: Bonding and coping with loss: Examining the construction of an intervention for multifetal pregnancy reduction procedures. Fetal Diagn Ther 2001;16:158-165.

4 Skrablin S, Kuvacic I, Pavicic D, Kalafatic D, Goluza T: Maternal neonatal outcome in quadruplet and quintuplet versus triplet gestations. Eur J Obstet Gynecol Reprod Biol 2000;88: 147.

5 French NP, Hagan R, Evans SF, Godfrey M, Newnham JP: Repeated antenatal corticosteroids: Size at birth and subsequent development. Am J Obstet Gynecol 1999;180:114.

6 Lee S: Retinopathy of prematurity in the 1990s. Neonat Netw 1999;18:31.

7 Coit AK: Necrotizing enterocolitis. J Perinat Neonat Nurs 1999; 12:53.

8 Schröder W: Mehrlingsschwangerschaft und Mehrlingsgeburt: Ein Leitfaden für die Praxis. Stuttgart, Thieme, 2001
9 Hadlock FP, Deter RL, Harrist RB, Park SK: Estimating fetal age: Computer-assisted analysis of multiple fetal growth parameters. Radiology 1984; $152: 497$.

10 Albrecht JL, Tomich PG: The maternal and neonatal outcome of triplet gestation. Am J Obstet Gynecol 1996;174:1551.

11 Jeffrey RL, Bowes WA, Delany JJ: Role of bed rest in twin gestation. Obstet Gynecol 1974;43: 822.

12 Newton ER: Antepartum care in multiple gestation. Semin Perinatol 1986;10:19.

13 ACOG Educational Bulletin: Special problems of multiple gestation. Int $\mathbf{J}$ Gynecol Obstet 1999;64:323.

14 Newman RB, Hamer C, Miller MC III: Outpatient triplet management: A contemporary review. Am J Obstet Gynecol 1989;161:547.

15 Vervliet J, De Cleyn K, Renier M, Janssens P, Buytaert P, Gerris J, Delbeke L: Management and outcome of 21 triplet and quadruplet pregnancies. Eur J Obstet Gynecol Reprod Biol 1989;33:61.

16 Crowther CA: Prevention of preterm birth in multiple pregnancy. Ballières Clin Obstet Gynaecol 1998;12:67.

17 Rush RW, Isaacs S, McPherson K, Jones L, Chalmers I, Grant A: A randomized controlled trial of cervical cerclage in women at high risk of spontaneous preterm delivery. Hum Reprod 1984; (suppl 6)2:724.

18 Strauss A, Hasbargen U, Hepp H: Wertigkeit der prophylaktischen Cerclage bei höhergradigen Mehrlingsschwangerschaften. Geburtsh Frauenheilk 2000;60(suppl 1):71.
19 Powers WE: Twin pregnancy: Complication and treatment. Obstet Gynecol 1973;42:795.

20 Knitza R, Ott M, Hasbargen U, Hepp H: Duration of the multifetal gestation, birth weight and infant prognosis. J Perinat Med 1993;21: 295.

21 Scherrer A: Gewichtsentwicklung höhergradiger Mehrlinge; Diss, LMU München 2001.

22 Collins MS, Bleyl JA: Seventy-one quadruplet pregnancies: Management and outcome. Am J Obstet Gynecol 1990;162:1384.

23 Holcberg G, Biale Y, Leventhal H, Insler V: Outcome of pregnancy in 31 triplet gestation. Obstet Gynecol 1982;59:472.

24 Gonen R, Heyman E, Asztalos EV, Ohlsson A, Pitson LC, Shennan AT, Milligan JE: The outcome of triplet, quadruplet and quintuplet pregnancies managed in a prenatal unit: $\mathrm{Ob}-$ stetric, neonatal and follow-up data. Am J Obstet Gynecol 1990;162:454.

25 Bryan EM: The Nature and Nuture of Twins. London, Ballière Tindall, 1983.

26 Kinsey VE: Retrolental fibroplasia: Cooperative study of retrolental fibroplasia and the use of oxygen. Arch Ophthalmol 1956;56:481.

27 Twinning P, McHugo JM, Pilling DW: Textbook of Fetal Abnormalities. London, Hartcourt Publishers, 2000.

28 Versmold HT: Outcome von 93 Drillingen, 55 Vierlingen und 15 Fünflingen; in Perinatale Medizin. Stuttgart, Dudenhausen, 1989.

29 Stanley FJ, Watson L: Trends in perinatal mortality and cerebral palsy in Western Australia 1967-1985. Br Med J 1992;304:1658. 